\title{
The relationship of childbirth experience with maternal functioning and mental health of Iranian women: A cross-sectional study
}

\section{Shiva Havizari}

Tabriz University of Medical Sciences

Solmaz Ghanbari Homayi

Tabriz University of Medical Sciences

Ommlbanin Eyvazzadeh

Tabriz University of Medical Sciences

Mojgan Mirghafourvand ( $\nabla$ mirghafourvand@gmail.com )

Tabriz University of Medical Sciences https://orcid.org/0000-0001-8360-4309

Research article

Keywords: Birth experience, Maternal functioning, Mental health

Posted Date: November 8th, 2019

DOI: https://doi.org/10.21203/rs.2.16953/v1

License: (c) (i) This work is licensed under a Creative Commons Attribution 4.0 International License.

Read Full License 


\section{Abstract}

Background: Childbirth experience is a major outcome of labor, which is always associated with some potential psychological advantages or damages. Given the significant impact of childbirth on maternal role and on physical and mental health of mothers, this study aimed to investigate the relationship of childbirth experience with postpartum maternal functioning and mental health of women.

Methods: This cross-sectional study was carried out on 483 mothers with vaginal childbirth, 4-16 weeks after delivery in health centers of Tabriz-Iran, 2018. The cluster random sampling method was used. The socio-demographic characteristics questionnaire, Questionnaire for Assessing the Childbirth Experience (QACE), Mental Health Inventory (MHI), and Barkin Index of Maternal Functioning (BIMF) were completed through interviews and the obtained data were analyzed using independent t-test, one-way ANOVA, Pearson's correlation test, and the General Linear Model (GLM).

Results: The mean score of childbirth experience was $1.6(0.4)$ within the score range of 1-4. The mean score of mental health was 79.1 (15.0) out of 18-108 and maternal functioning was 97.4 (13.0) out of 0120. Based on the correlation coefficients, there were significant correlations between the total score of mental health and maternal functioning and all its subdomains with childbirth experience $(P<0.001)$, also based on GLM results, maternal functioning was significantly correlated with childbirth experience $(P<0.001)$, receiving help for infant care $(P<0.001)$ and the adequacy of family income $(P=0.006)$. Mental health was significantly correlated with childbirth experience $(P<0.001)$, complete life-satisfaction $(P<0.001)$, and receiving help for infant care $(P=0.025)$.

Conclusion: The results showed significant relationships between childbirth experience with maternal functioning, mental health and all their subdomains. Considering these relationships, it seems that supportive care services offered by health care providers can improve mothers' birth experiences and consequently lead to improved postpartum maternal functioning and mental health.

\section{Background}

One of the most important developments in women's lives is transition to the maternal stage [1], which is associated with adjustment to new maternal roles and responsibilities, as well as with many physical, social, and psychological changes [2]. Giving birth to a baby is often regarded as a positive and natural event in a woman's life; however, for many women childbirth experience may be a combination of positive and negative (or a series of negative) experiences [3].

Childbirth experience is a significant reality of life that may affect a woman's short/long-term health. Allegedly, $20-48 \%$ of women worldwide have reported birth trauma, which is linked with adverse mental health effects on mothers, maternal bond, and infant growth and development [4]. Having a history of psychological disorders, being a first-time mother, and undergoing $\mathrm{C}$-section are identified as risk factors for traumatic childbirth [5]. The first experience of labor affects one's attitude towards subsequent deliveries [6], and negative experiences increase the risk of postpartum depression in the current and 
subsequent deliveries [7]. Moreover, mental disorders can have long-term negative effects on mothers and, if left untreated, on children's mental health [8].

According to World Health Organization, mental health is "a state of well-being in which the individual realizes his or her own abilities, can cope with the common stresses of life, can work productively and efficiently, and is able to make a contribution to his or her community" [9]. In developing countries, 1 in 35 women experience major mental health problems during pregnancy and after childbirth; however, the ratio is about $10 \%$ in developed countries [10]. Women's emotional and mental health significantly influences their perception and experiences of pregnancy and labor [11]. A cohort study was conducted on 175 mothers in Canada one month after childbirth. Based on the results, women's birth experience fails to predict early parenting behaviors; however, mental health significantly predicts positive parenting behaviors one month after childbirth [12].

In addition to the status of depression, mental health characteristics are also affected by other constructs such as maternal functioning, which is measured with regard to a woman's adaptation to her new maternal roles. Childbirth experience influences mothers' perception of infants and their description of postpartum caring behaviors [13]. The studies of Teti et al. indicate that mother's assessment of her child affects early child care behaviors and their mutual relationship, and that her poor understanding of her child is associated with poor behavioral skills and a sense of poor maternal competence $[14,15]$. Postpartum functioning significantly influences the establishment and maintenance of a successful mother-child relationship, and a high level of maternal functioning is likely to be associated with positive infant development outcomes. Factors that may affect postpartum functioning in the general population include parity, childbirth experience, type of delivery, and maternal and newborn complications [16].

Few studies have investigated childbirth experiences in Iran. In their qualitative study on childbirth experience of primiparous women in Shiraz, Iran, Vaziri et al. found that these women do not have realistic expectations of natural childbirth. In addition to focusing on maternal and fetal health, their study emphasized the importance of antenatal classes, and increased support for mothers [17]. Given the importance of childbirth experiences and their short/long-term effects on women and infants [18], and also due to a gap in the literature to assess the relationship between the childbirth experience and mental health variables and maternal functioning, this study aimed to investigate the relationship of childbirth experience with maternal functioning and mental health of Iranian women.

\section{Methods}

\section{Study design and participants}

\section{This cross-sectional descriptive-analytical study was carried out in 2018 in health centers of Tabriz, Iran, on $\mathbf{4 8 3}$ mothers with vaginal childbirth 4-16 weeks after delivery.}


Women with a singleton first pregnancy and gestational age of $\geq 38$ weeks, normal pregnancy and natural labor, and perfect perceived physical health who were willing to participate in the study were enrolled. The exclusion criteria included suffering from/having a history of mental illnesses, experiencing a stressful life event in the past three months, hospitalized neonate due to a postpartum illness, neonate abnormality, and refusing to complete the questionnaire.

\section{Sample size}

Based on the results of Ghanbari-Homayi et al. (2019) study and with considering the Standard Deviation $(S D)=0.73$, precision $(d)=0.05$ around the mean $(m=2.71), a=0.05$ and power $=90$, the sample size was calculated as 226 . With considering the design effect equal with 2 due to cluster sampling method, the final sample size was calculated as 452 and 483 individuals were selected as the final sample to compensate for the potential loss to follow-up [19].

\section{Sampling}

After obtaining the approval of the Ethics Committee of Tabriz University of Medical Sciences (ethical code: IR.TBZMED.REC.1397.147), one-fourth of all health centers in Tabriz were selected using the website www.random.org and through cluster random sampling. Using available health records, the list of mothers in their 4-16 postpartum weeks was prepared, and the number of samples per health center was determined randomly using proportional allocation. The researcher called the selected mothers and asked them to attend the respective health center at a specific time. The participants were fully informed about the research objectives. Then, they signed written consent forms and completed the questionnaires.

\section{Data Collection Tool}

The data were collected using the socio-demographic, the short form Questionnaire for assessing the Childbirth Experience (QACE), Mental Health Inventory (MHI), and Barkin Index of Maternal Functioning (BIMF).

A researcher-made socio-demographic questionnaire was used to obtain information about mother's age, educational qualifications of mother and her spouse, their job, their income status, infant's gender, pregnancy status (planned or unwanted), etc. The content and face validity of this questionnaire was confirmed.

The QACE was used to collect relevant data. The thematic areas of this 13 -item tool included feelings (items 1, 2, and 3), relationship with staff (items 4, 5, 6, and 7), first moments with the infant (items 8, 9, and 10), and feelings one month after the delivery (items 11, 12, and 13). Items 8-13 measured the consequences of this experience. The responses included completely (score 1), relatively (score 2), not much (score 3), and not at all (score 4), which were scored using a 4-point Likert scale. The negatively 
worded items (including items 1, 12, and 13) were reversely scored; thus, higher scores indicated a more negative experience [20]. The reliability of this questionnaire was measured using test-retest design and by conducting a pilot study on 20 individuals with a two-week interval and it was confirmed by determining intra-class correlation coefficient (ICC $=0.83(0.56$ to 0.93$))$ and Cronbach's alpha coefficient (0.82).

A questionnaire was used to collect the data related to maternal functioning. The thematic areas of this 20 -item tool included self-care (items 2, 11, and 13), infant care (items 12 and 14); mother-child interaction (items 4, 5, and 15); psychological well-being (items 1, 2, 3, 5, 7, 10, 11, 16, 18, and 20); social support (items 6, 8, and 9); management (items 7, 11, 13, 14, 17, and 18), and adjustment (items 17 and 19). The responses included "strongly disagree", "disagree", "somewhat disagree", "no idea", "somewhat agree", "agree", and "strongly agree". The mothers were asked to answer questions based on their feelings over the past two weeks. The negatively worded items (i.e. items 16 and 18) were reversely scored and a total maternal functioning score ranged from 0 to 120 . Higher total scores indicated higher levels of functioning. The Cronbach's alpha and reliability coefficients of the tool were reported as 0.88 and 0.88 [21], respectively. In the present study, the Cronbach's alpha coefficient of the questionnaire was 0.88 , and those of the relevant constructs were 0.78 (maternal competence) and 0.86 (maternal needs), which indicate an acceptable internal consistency. In the test-retest method, the intra-cluster correlation coefficient was 0.85 for the whole questionnaire, and those of maternal needs and maternal competence constructs were 0.89 and 0.88 , respectively.

The Mental Health Inventory (MHI) of Veit and Ware was used to collect relevant mental health data. This tool has a short (18 items) and a long (38 items) form. The MHI is superior to other scales (such as the General Health Questionnaire), because it has been designed for normal populations, while the GHQ is a diagnostic tool used for clinical populations. The short form of MHI was used in this study, which is an 18-item screening tool used for measuring mental health in two areas of adults' general health and psychological distress. The responses included always (score 1), often (score 2), most times (score 3), sometimes (score 4), rarely (score 5), and never (score 6). The negatively worded items (i.e. items 1, 3, 5, $7,8,10,13$, and 15) were reversely scored. The subdomains of "anxiety", "depression", "behavioral control", and "positive affect" consisted of items " $4,6,10,11,18$ ", "2, 9, 12, 14", " $5,8,16,17$ ", and "1, 7, 13, 15 ", respectively. Meybodi et al. [22] and Veit [23] et al. evaluated the psychometric performance of this tool. Cronbach's alpha coefficient was calculated to measure the internal consistency of the tool. The alpha coefficient was 0.93 for the whole inventory, and those of anxiety, depression, behavioral control, and positive affect were $0.84,0.83,0.63$, and 0.85 , respectively. These findings indicated an acceptable internal consistency.

\section{Data analysis}

The collected data were analyzed in SPSS 24 software. Skewness and Kurtosis were measured to determine if the qualitative data were normally distributed. In bivariate analysis, Pearson's correlation 
tests were conducted to determine the correlation between maternal functioning, mental health and their subdomains with childbirth experience. In addition, one-way ANOVA and independent t-test were performed to determine the relationship between socio-demographic characteristics with maternal functioning and mental health. In multivariate analysis, General Linear Model (GLM) was used to determine the relationship between childbirth experience with maternal functioning and mental health, while the variable of socio-demographic characteristics was considered as the control variables.

\section{Results}

The mean weight of the infants was 3129.6 (511.7) gram. Most of the mothers (95.1\%) were housewives, and the more than one-third of mothers (36.8) and their spouses (36.2) had a high school diploma. Most families $(74.2 \%)$ had average income levels. Nearly half of the mothers $(40.2 \%)$ lived in rented houses, $76.6 \%$ of the mothers lived with their spouses, and $76 \%$ tended to become pregnant. In $93 \%$ of the cases, both mother and father were satisfied with their baby's gender. About two-thirds of the participants $(63.2 \%)$ received help with childcare $(21.5 \%$ received help from their spouses and $20.9 \%$ from their mothers). About half of the mothers (50.0\%) were entirely satisfied with their lives (Table 1 ).

The mean score of childbirth experience was $1.6(0.4)$ within the score range of $1-4$. The mean score of mental health was 78.4 (14.9) (out of 18-108). The mean score of mental health and subdomains including anxiety, depression, behavioral control, and positive affect were 21.6 (4.7), 18.7 (4.1), 16.8 (2.8), and 16.9 (4.1), respectively (out of 6-30).

The mean score of maternal functioning was 96.8 (13.0) (out of $0-120$ ), and the mean score of its subdomains included: self-care 14.4 (3.2) (out of 6-18), infant care 11.1 (1.2) (out of 6-12), mother-child interaction 14.9 (2.4) (out of 6-18), psychological well-being 47.0 (6.9) (out of 6-60), social support 13.5 (3.8) (out of 6-18), management 27.6 (5.0) (out of 6-36), and adjustment 10.6 (1.6) (out of 6-12).

Based on the correlation coefficients, there were significant correlations between childbirth experience and the total score of mental health $(P<0.001, r=-0.35)$ and all its subdomains $(P<0.001, r=-0.29$ to 0.35). In addition, there were significant relationships between childbirth experience and the total score of maternal functioning $(P<0.001, r=-0.32)$ and all its subdomains $(P<0.001, r=-0.16$ to -0.32$)$ (Table 2).

The GLM results showed that maternal functioning had significant relationships with childbirth experience $(P<0.001)$, receiving help for infant care $(P<0.001)$, and the adequacy of family income $(P=$ 0.006) (Table3). According to the Table 4 (GLM results), mental health was significantly correlated with childbirth experience $(P<0.001)$, complete life-satisfaction $(P<0.001)$, and receiving help for infant care $(P$ $=0.025$ ).

\section{Discussion}


Maternal functioning and mental health scores were relatively desirable, and there were significant relationships between maternal functioning, mental health and all their subdomains with childbirth experience. Maternal functioning and mental health were both correlated with childbirth experience and receiving help for infant care. Also, maternal functioning was significantly correlated with the adequacy of family income and mental health was significantly correlated with complete life-satisfaction.

In the present study, maternal functioning was correlated with childbirth experience. In the study of Bryanton et al. (2009), childbirth experience did not predict early parental behaviors (feeding, protecting from harm, etc.); however, having a vaginal delivery, enjoying a good mental health, and having high educational qualifications were associated with positive maternal behaviors [12]. This is not consistent with the present study, which may be due to the effect of other relevant factors on maternal functioning. In some studies, negative or traumatic childbirth experiences were correlated with mother-child interaction issues [24, 25]. Bell et al. (2018) found that women who experience a positive birth provide the best maternal care and behaviors at 1 and 8 months after birth [26], which is consistent with the present study.

The results of this study showed a significant relationship between mental health and childbirth experience. In their systematic review, Bell et al.2016) found significant relationships between women's birth experience and postpartum depression in 11 (out of 15) studies [27], which is in line with the present results. A prospective cohort study (2016) showed that negative childbirth experience is associated with aggravated anxiety symptoms in mothers at 2 and 8 months after birth, and that an improvement in birth experience can reduce postpartum anxiety in mothers [28]. Gurber et al. (2017) found that parents' subjective experience of birth facilitates their postpartum psychological adjustment [29], which is consistent with the present study.

There was a significant correlation between receiving help from others and maternal functioning, as mothers who had received postpartum help achieved higher functioning scores. Seighali et al. (2014) found that holding breastfeeding workshops can improve mothers' knowledge and their postpartum functioning [30], which is consistent with the present results. Bryanton et al.2009) introduced partner support and help as an important determinant of maternal behavior and functioning [12], which is consistent with the present study. In addition, in this study, high family income levels were associated with higher maternal functioning scores.

In another study, Goyal et al.2010) investigated the risk of depression in first-time mothers with low socioeconomic status (low literacy, low income, etc.). The results showed high prevalence of depression among these mothers [31], and this is in line with the present study, because poor postpartum mental health leads to poor mother-child interaction and poor maternal functioning. In addition, there was a significant relationship between satisfaction with life and postpartum mental health. Salehi et al.(2010) reported a high prevalence of postpartum depression among mothers with marital problems, and argued that marital problems can lead to poor spouse support (provided to mothers and birth attendants) and may cause subsequent postpartum problems [32]. This finding is in line with the present results. 
The results indicated a significant relationship between receiving help and mental health. In this regard, Horowitz et al. (2005) stated that poor spouse support is a major cause of postpartum depression [33]. Anderson et al. (2012) conducted a systematic review and identified lack of support (especially by spouse) as an important predictor of PTSD (Post Traumatic Stress Disorder) [34]. Accordingly, studies of Cigoli (2006) and Nicholls (2007) are consistent with the present study [35, 36].

Some of the strengths of this study include the novelty of its subject, its large sample size, and the use of random sampling. The participants were selected among women visiting some urban health centers; therefore, the results cannot be generalized to rural women or to those who undergo cesarean section. The findings can serve as a guide for future studies and can help professionals working in various maternal health centers. Researchers are recommended to conduct studies, especially clinical trials, to improve mothers' adjustment with postnatal conditions and their childbirth experiences.

\section{Conclusions}

The results showed significant relationships between maternal functioning, mental health and all their subdomains with childbirth experience. Considering these relationships, it seems that supportive care services offered by health care providers can improve mothers' birth experiences and enhance their selfesteem, trust, respect, and sense of security, and consequently lead to improved postpartum maternal functioning and mental health.

\section{Abbreviations}

QACE: Questionnaire for Assessing the Childbirth Experience; MHI: Mental Health Inventory; BIMF: Barkin Index of Maternal Functioning; GLM: General Linear Model.

- Acknowledgements

- We hereby wish to thank Tabriz University of Medical Sciences to support this research, all participants in this study and personnel at the healthcare centers in Tabriz for their sincere cooperation in sampling.

\section{Declarations}

- Authors contributions

- MM supervised and collaborated on title selection, formulation of problem statement, methodology design, project design, data analysis and final report writing and article writing. SGH collaborated on title selection, formulation of problem statement, methodology design, project design, and final report writing and article writing. SH Contributed to literature review, questionnaire distribution and collection, data analysis and article writing. EO contributed to project design, data collection and prepared the first draft of the manuscript. All authors read and approved the final manuscript. 


\section{Funding}

\section{This study was funded by Tabriz University of Medical Sciences, Iran.}

- Availability of data and materials

- All data generated or analyzed during this study are included in this published article and its supplementary information files.

\section{Ethics approval and consent to participate}

Written informed consent was obtained from all participants. The study received ethical approval from the Tabriz University of Medical Sciences (ethical code: IR.TBZMED.REC.1397.147). The authors assert that the study complies with the Helsinki Declaration of 1975, as revised in 2008 and no organs/tissues were obtained from prisoners and only participants received counseling.

\section{Consent for publication}

\section{Not applicable}

- Competing interests

- The authors declare that they have no competing interests.

\section{References}

1. Aydın R, Kukulu K. Adaptation of the Barkin scale of maternal functioning and examination of the psychometric properties. Health Care Women Int. 2018;39(1):50-64.

2. Don BP, Chong A, Biehle SN, Gordon A, Mickelson KD. Anxiety across the transition to parenthood: change trajectories among low-risk parents. Anxiety Stress Coping. 2014;27(6):633-49.

3. Thomson G, Garrett C. Afterbirth support provision for women following a traumatic/distressing birth: Survey of NHS hospital trusts in England. Midwifery. 2019:63-70.

4. Simpson M, Catling C. Understanding psychological traumatic birth experiences: A literature review. Women and birth : Aust J Midwifery. 2016;29(3):203-7.

5. Beck CT, Gable RK, Sakala C, Declercq ER. Posttraumatic stress disorder in new mothers: Results from a two-stage US national survey. Birth. 2011;38(3):216-27.

6. Karlström A, Nystedt A, Johansson M, Hildingsson I. Behind the myth-few women prefer caesarean section in the absence of medical or obstetrical factors. Midwifery. 2011;27(5):620-7. 
7. Rijnders M, Baston H, Schönbeck Y, Van Der Pal K, Prins M, Green J, et al. Perinatal factors related to negative or positive recall of birth experience in women 3 years postpartum in the Netherlands. Birth. 2008;35(2):107-16.

8. Vigod S, Sultana A, Fung K, Hussain-Shamsy N, Dennis C-L. A population-based study of postpartum mental health service use by immigrant women in Ontario, Canada. Can J Psychiatry. 2016;61(11):705-13.

9. Galderisi S, Heinz A, Kastrup M, Beezhold J, Sartorius N. Toward a new definition of mental health. World Psychiatry. 2015;14(2):231-3.

10. World Health Organization. Maternal mental health and child health and development in resourceconstrained settings: report of a UNFPA. Geneva: WHO; 2009.

11. Fenwick J, Toohill J, Gamble J, Creedy DK, Buist A, Turkstra E, et al. Effects of a midwife psychoeducation intervention to reduce childbirth fear on women's birth outcomes and postpartum psychological wellbeing. BMC Pregnancy Childbirth. 2015;15(1):284.

12. Bryanton J, Gagnon AJ, Hatem M, Johnston C. Does perception of the childbirth experience predict women's early parenting behaviors?. Res Nurs Health. 2009;32(2):191-203.

13. Reisz S, Jacobvitz D, George $C$. Birth and motherhood: childbirth experience and mothers perceptions of themselves and their babies. Infant Ment Health J. 2015;36(2):167-78.

14. Teti DM, Gelfand DM. Maternal cognitions as mediators of child outcomes in the context of postpartum depression. In L. Murray \& P. J. Cooper (Eds.), Postpartum depression and child development (). New York, NY, US: Guilford Press. 1997; pp. 136-164.

15. Jameson PB, Gelfand DM, Kulcsar E, Teti DM. Mother-toddler interaction patterns associated with maternal depression. Dev Psychopathol. 1997;9(3):537-50.

16. Gjerdingen DK, Center BA. First-time parents' prenatal to postpartum changes in health, and the relation of postpartum health to work and partner characteristics. J Am Board Fam Pract.2003;16(4):304-11.

17. Vaziri farideh Kz, Morshed Behbahani bahareh. Qualitative investigation of experiences and perception of primiparous women regarding childbirth in women referring to educational hospitals of Shiraz University of Medical Sciences. J Birjand Univ Med Sci. 2012;9(3):226-36.

18. Mirghafourvand M, Mohammad Alizadeh Charandabi S, Ghanbari-Homayi S, Jahangiry L, Nahaee J, Hadian T. Effect of birth plans on childbirth experience: A systematic review. Int J Nurs Pract. 2019:e12722.

19. Ghanbari-Homayi S, Fardiazar Z, Meedya S, Mohammad-Alizadeh-Charandabi S, Asghari-Jafarabadi $M$, Mohammadi E, et al. Predictors of traumatic birth experience among a group of Iranian primipara women: a cross sectional study. BMC Pregnancy Childbirth. 2019;19(1):182.

20. Carquillat P, Vendittelli F, Perneger T, Guittier M-J. Development of a questionnaire for assessing the childbirth experience (QACE). BMC Pregnancy Childbirth. 2017;17(1):279.

21. Barkin JL, Wisner KL, Bromberger JT, Beach SR, Terry MA, Wisniewski SR. Development of the Barkin index of maternal functioning. J Women's Health. 2010;19(12):2239-46. 
22. Meybodi FA, Saeedi Z, Behjati Z, Noorbala F, Dastbaravardec A, Enjedany E. Reliability and validity of a Farsi version of 18-item Mental Health Inventory. Procedia Soc Behav Sci. 2011;30 (1):1425-9.

23. Veit CT, Ware JE. The structure of psychological distress and well-being in general populations. $J$ Consult Clin Psychol. 1983; 51(5):730.

24. Ballard C, Stanley A, Brockington I. Post-traumatic stress disorder (PTSD) after childbirth. Br J Psychiatry. 1995;166(4):525-8.

25. Reynolds JL. Post-traumatic stress disorder after childbirth: the phenomenon of traumatic birth. Can Med Assoc J. 1997;156(6):831-5.

26. Bell A, Rubin L, Davis J, Golding J, Adejumo O, Carter C. The birth experience and subsequent maternal caregiving attitudes and behavior: a birth cohort study. Arch Womens Ment Health. 2018,1:1-8.

27. Bell AF, Andersson E. The birth experience and women's postnatal depression: A systematic review. Midwifery. 2016;39:112-23.

28. Bell A, Carter C, Davis J, Golding J, Adejumo O, Pyra M, et al. Childbirth and symptoms of postpartum depression and anxiety: a prospective birth cohort study. Arch Womens Ment Health. 2016;19(2):21927.

29. Gürber S, Baumeler L, Grob A, Surbek D, Stadlmayr W. Antenatal depressive symptoms and subjective birth experience in association with postpartum depressive symptoms and acute stress reaction in mothers and fathers: A longitudinal path analysis. Eur J Obstet Gynecol Reprod Biol. 2017;215:68-74.

30. Seighali F FM, Farahani Z. The effect of breastfeeding workshop on attitude, knowledge and practice of participants. Razi J Med Sci. 2014;21(118):92-101.

31. Barkin JL, Wisner KL, Bromberger JT, Beach SR, Terry MA, Wisniewski SR. Development of the Barkin index of maternal functioning. J Womens Health. 2010;19(12):2239-46.

32. Meybodi FA, Saeedi Z, Behjati Z, Noorbala F, Dastbaravardec A, Enjedany E. Reliability and validity of a Farsi version of 18-item Mental Health Inventory. Procedia-Social and Behavioral Sciences. 2011;30:1425-9.

33. Veit CT, Ware JE. The structure of psychological distress and well-being in general populations. J Consult Clin Psychol. 1983;51(5):730.

34. Ballard C, Stanley A, Brockington I. Post-traumatic stress disorder (PTSD) after childbirth. British J Psychiatry. 1995;166(4):525-8.

35. Reynolds JL. Post-traumatic stress disorder after childbirth: the phenomenon of traumatic birth. CMAJ. 1997;156(6):831-5.

36. Bell A, Rubin L, Davis J, Golding J, Adejumo O, Carter C. The birth experience and subsequent maternal caregiving attitudes and behavior: a birth cohort study. Arch Womens Ment Health. 2018:1-8.

37. Bell AF, Andersson E. The birth experience and women's postnatal depression: A systematic review. Midwifery. 2016;39:112-23. 
38. Bell A, Carter C, Davis J, Golding J, Adejumo O, Pyra M, et al. Childbirth and symptoms of postpartum depression and anxiety: a prospective birth cohort study.

Arch Womens Ment Health. 2016;19(2):219-27.

39. Gürber S, Baumeler L, Grob A, Surbek D, Stadlmayr W. Antenatal depressive symptoms and subjective birth experience in association with postpartum depressive symptoms and acute stress reaction in mothers and fathers: A longitudinal path analysis. Eur J Obstet Gynecol Reprod Biol . 2017;215:6874.

40. Seighali F FM, Farahani Z. The effect of breastfeeding workshop on attitude, knowledge and practice of participants Razi J Med Sci. 2014;21(118):92-101.

41. Goyal D, Gay C, Lee KA. How much does low socioeconomic status increase the risk of prenatal and postpartum depressive symptoms in first-time mothers? Womens Health Issues. 2010;20(2):96-104.

42. Salehi L TS, Salehi F. The study of demographic characteristics affecting postpartum depression. Adv Nurs Midwifery. 2010;19(64):31-25.

43. Horowitz JA, Damato EG, Duffy ME, Solon L. The relationship of maternal attributes, resources, and perceptions of postpartum experiences to depression. Res Nurs Health. 2005;28(2):159-71.

44. Andersen LB, Melvaer LB, Videbech P, Lamont RF, Joergensen JS. Risk factors for developing posttraumatic stress disorder following childbirth: a systematic review. Acta Obstet Gynecol Scand.2012;91(11):1261-72.

45. Cigoli V, Gilli G, Saita E. Relational factors in psychopathological responses to childbirth. J Psychosom Obstet Gynaecol. 2006;27(2):91-7.

46. Nicholls K, Ayers S. Childbirth-related post-traumatic stress disorder in couples: A qualitative study. Br J Health Psychol. 2007;12(4):491-509.

\section{Tables}

Table 1: Demographic characteristics of participants 


\begin{tabular}{|c|c|c|c|}
\hline Variable & Number (Percent) & Variable & Number (Percent) \\
\hline Weight of newborn ${ }^{*}$ & $3129.6(511.7)$ & House status & \\
\hline Gestational age* & $38.5(2.1)$ & Personal & $168(34.8)$ \\
\hline Mother's age ${ }^{*}$ & $27.0(5.4)$ & Hire & $199(41.2)$ \\
\hline Husband's age* & $31.9(5.2)$ & Parent's House & $8(1.7)$ \\
\hline Mother's job & & Husband parent's House & $106(21.9)$ \\
\hline House wife & $462(95.7)$ & Organizational house & $2(0.4)$ \\
\hline Employed & $21(4.3)$ & Living with & \\
\hline Husband`s job & & Husband & $366(75.8)$ \\
\hline Unemployed & $10(2.1)$ & Alone & $4(0.8)$ \\
\hline Worker & $148(30.6)$ & Family & $10(2.1)$ \\
\hline Employee & $58(12.0)$ & Husband's family & $103(21.3)$ \\
\hline Self-employee & $256(53.0)$ & Sex of newborn & \\
\hline Other & $11(2.3)$ & Girl & $249(51.6)$ \\
\hline Education & & Boy & $234(48.4)$ \\
\hline Primary school & $64(13.3)$ & Wanted pregnancy & \\
\hline Secondary school & $94(19.5)$ & Yes & $363(75.2)$ \\
\hline High school & $65(13.5)$ & No & $120(24.8)$ \\
\hline Diploma & $172(35.6)$ & Interest in sexuality of newborn & \\
\hline University & $88(18.2)$ & None & $17(3.5)$ \\
\hline Husband's education & & Both me and my husband & $449(93.0)$ \\
\hline Primary school & $62(12.8)$ & Only me & $10(2.1)$ \\
\hline Secondary school & $114(23.6)$ & Only my husband & $7(1.4)$ \\
\hline High school & $51(10.6)$ & Receiving help for infant care & \\
\hline Diploma & $178(36.9)$ & Yes & $301(62.3)$ \\
\hline University & $78(16.1)$ & No & $182(37.7)$ \\
\hline Sufficiency of Income & & Who help you & \\
\hline Sufficient & $45(9.3)$ & Husband & $105(21.7)$ \\
\hline Relatively sufficient & $364(75.4)$ & Mother & $100(20.7)$ \\
\hline Insufficient & $74(15.3)$ & Mother-in-low & $66(13.7)$ \\
\hline Satisfaction of life & & Sister & $7(1.4)$ \\
\hline Absolutely & $229(47.4)$ & Sister-in-low & $2(0.4)$ \\
\hline Moderate & $247(51.1)$ & Other & $21(4.3)$ \\
\hline Not at all & $7(1.4)$ & & \\
\hline
\end{tabular}

*Data was reported as mean (Standard Deviation)

Table 2: Birth experience, maternal functioning and mental health status and relationship between maternal function and mental health and its subscales with birth experience 


\begin{tabular}{|c|c|c|c|c|c|}
\hline \multirow[t]{2}{*}{ Variable } & \multirow[t]{2}{*}{$\begin{array}{l}\text { Mean } \\
\text { (SD) }\end{array}$} & \multirow{2}{*}{$\begin{array}{c}\text { Achieved score } \\
\text { range } \\
\text { (Min to Max) }\end{array}$} & \multirow[t]{2}{*}{$\begin{array}{l}\text { Achievable score } \\
\text { range }\end{array}$} & \multicolumn{2}{|c|}{$\begin{array}{c}\text { Relationship with birth } \\
\text { experience }\end{array}$} \\
\hline & & & & $r^{*}$ & $\mathrm{P}^{*}$ \\
\hline Birth experience & $1.6(0.4)$ & 1 to 3.5 & 1 to 4 & - & - \\
\hline Mental health & $\begin{array}{r}78.4 \\
(14.9)\end{array}$ & 28 to 108 & 18 to 108 & -0.35 & $>0.001$ \\
\hline Anxiety & $\begin{array}{l}21.6 \\
(4.7)\end{array}$ & 6 to 30 & 6 to 30 & -0.29 & $>0.001$ \\
\hline Depression & $\begin{array}{r}18.7 \\
(4.1)\end{array}$ & 4 to 24 & 6 to 30 & -0.35 & $>0.001$ \\
\hline Behavior control & $\begin{array}{l}16.8 \\
(2.8)\end{array}$ & 5 to 24 & 6 to 30 & -0.28 & $>0.001$ \\
\hline Positive mood & $\begin{array}{l}16.9 \\
(4.1)\end{array}$ & 5 to 24 & 6 to 30 & -0.32 & $>0.001$ \\
\hline Maternal function & $\begin{array}{r}96.8 \\
(13.0)\end{array}$ & 41 to 120 & 0 to 120 & -0.32 & $>0.001$ \\
\hline Self-care & $\begin{array}{l}14.4 \\
(3.2)\end{array}$ & 2 to 18 & 6 to 18 & -0.28 & $>0.001$ \\
\hline Newborn care & $\begin{array}{l}11.1 \\
(1.2)\end{array}$ & 4 to 12 & 6 to 12 & -0.30 & $>0.001$ \\
\hline $\begin{array}{l}\text { Mother child } \\
\text { interaction }\end{array}$ & $\begin{array}{r}14.9 \\
(2.4)\end{array}$ & 7 to 18 & 6 to 18 & -0.21 & $>0.001$ \\
\hline $\begin{array}{l}\text { Maternal } \\
\text { psychological }\end{array}$ & $\begin{array}{l}47.0 \\
(6.9)\end{array}$ & 19 to 60 & 6 to 60 & -0.31 & $>0.001$ \\
\hline Social support & $\begin{array}{l}13.5 \\
(3.8)\end{array}$ & 3 to 18 & 6 to 18 & -0.16 & 0.001 \\
\hline Management & $\begin{array}{r}27.6 \\
(5.0)\end{array}$ & 8 to 36 & 6 to 36 & -0.32 & $>0.001$ \\
\hline Adjustment & $\begin{array}{r}10.6 \\
(1.6) \\
\end{array}$ & 2 to 12 & 6 to 12 & -0.30 & $>0.001$ \\
\hline
\end{tabular}

${ }^{*}$ The results are based on Pearson correlation test

Table 3: Relationship between birth experience and maternal function based on general linear model 


\begin{tabular}{|c|c|c|}
\hline Variable & B (95\% CI*) & $\mathbf{P}$ \\
\hline Birth experience & $-7.0(-9.3$ to -4.6$)$ & $>0.001$ \\
\hline \multicolumn{3}{|l|}{ Interest in sexuality of newborn } \\
\hline None & 0.5 (-9.3 to 10.4$)$ & 0.914 \\
\hline Both me and my husband & $6.5(-1.8$ to 14.9$)$ & 0.128 \\
\hline Only me & $-1.1(-12.0$ to 9.8$)$ & 0.842 \\
\hline Only my husband (Reference) & 0 & \\
\hline \multicolumn{3}{|l|}{ Receiving help for infant care } \\
\hline Yes & 6.1 (4.0 to 8.2$)$ & $0.001>$ \\
\hline No (Reference) & 0 & \\
\hline \multicolumn{3}{|l|}{ Satisfaction of life } \\
\hline Completely & $3.5(-5.1$ to 12.2$)$ & 0.425 \\
\hline Relatively & $-3.8(-12.5$ to 4.8$)$ & 0.384 \\
\hline Not at all (Reference) & 0 & \\
\hline \multicolumn{3}{|l|}{ Sufficiency of income } \\
\hline Sufficient & $-2.4(-6.7$ to 1.9$)$ & 0.278 \\
\hline Relatively sufficient & $-4.1(-7.0$ to -1.2$)$ & 0.006 \\
\hline Insufficient (Reference) & 0 & - \\
\hline Mother's age & $-0.1(-0.4$ to 0.1$)$ & 0.371 \\
\hline Husband's age & $-0.04(-0.2$ to 0.3$)$ & 0.788 \\
\hline
\end{tabular}

*95\%Confidence Interval

Table 4: Relationship between birth experience and mental health based on general linear model 


\begin{tabular}{|c|c|c|}
\hline Variable & B $\left(95 \% \mathrm{CI}^{*}\right)$ & $P$ \\
\hline Birth experience & $-9.0(-11.7$ to -6.2$)$ & $<0.001$ \\
\hline \multicolumn{3}{|l|}{ Interest in sexuality of newborn } \\
\hline None & $5.9(-5.7$ to 17.5$)$ & 0.318 \\
\hline Both me and my husband & $5.9(-4.0$ to 15.7$)$ & 0.240 \\
\hline Only me & $-1.7(-14.4$ to 11.1$)$ & 0.796 \\
\hline Only my husband (Reference) & 0 & \\
\hline \multicolumn{3}{|l|}{ Receiving help for infant care } \\
\hline Yes & $2.9(-0.3$ to 5.3$)$ & 0.025 \\
\hline No (Reference) & 0 & \\
\hline \multicolumn{3}{|l|}{ Satisfaction of life } \\
\hline Completely & 17.0 (6.6 to 27.5$)$ & 0.001 \\
\hline Relatively & $9.1(-1.2$ to 19.5$)$ & 0.084 \\
\hline Not at all (Reference) & 0 & \\
\hline \multicolumn{3}{|l|}{ Sufficiency of Income } \\
\hline Sufficient & $1.4(-3.8$ to 6.5$)$ & 0.601 \\
\hline Relatively sufficient & $1.0(-2.5$ to 4.5$)$ & 0.577 \\
\hline Insufficient (Reference) & 0 & \\
\hline Mother's age & $-0.2(-0.5$ to 0.1$)$ & 0.243 \\
\hline Husband's age & $0.1(-0.2$ to 0.4$)$ & 0.427 \\
\hline \multicolumn{3}{|l|}{ Husband's job } \\
\hline Unemployed & $1.7(-9.7$ to 13.1$)$ & 0.766 \\
\hline Worker & $2.9(-5.2$ to 11.0$)$ & 0.477 \\
\hline Employee & $-0.2(-8.3$ to 8.9$)$ & 0.948 \\
\hline Self-employment & $-2.2(-10.2$ to 5.9$)$ & 0.594 \\
\hline Other (Reference) & 0 & \\
\hline
\end{tabular}

*95\%Confidence Interval 